\title{
Explosion dynamics of pyroclastic eruptions at Santiaguito Volcano
}

\author{
Jeffrey B. Johnson, ${ }^{1,2}$ Andrew J. L. Harris, ${ }^{1}$ Steve T. M. Sahetapy-Engel, ${ }^{1}$ Rudiger Wolf, ${ }^{3}$ \\ and William I. Rose ${ }^{4}$
}

Received 14 November 2003; revised 26 January 2004; accepted 24 February 2004; published 20 March 2004.

[1] In Jan. 2003 we monitored explosions at Santiaguito Volcano (Guatemala) with thermal, infrasonic, and seismic sensors. Thermal data from 2 infrared thermometers allowed computation of plume rise speeds, which ranged from 8 to $20 \mathrm{~m} / \mathrm{s}$. Rise rates correlated with cumulative thermal radiance, indicating that faster rising plumes correspond to explosions with greater thermal flux. The relationship between rise speeds and elastic energy is less clear. Seismic radiation may not scale well with thermal output and/or rise speed because some of the thermal component may be associated with passive degassing, which does not induce significant seismicity. But non-impulsive gas release is still able to produce a high thermal flux, which is the primary control on buoyant rise speed. INDEX TERMS: 8414 Volcanology: Eruption mechanisms; 8419 Volcanology: Eruption monitoring (7280); 8494 Volcanology: Instruments and techniques. Citation: Johnson, J. B., A. J. L. Harris, S. T. M. Sahetapy-Engel, R. Wolf, and W. I. Rose (2004), Explosion dynamics of pyroclastic eruptions at Santiaguito Volcano, Geophys. Res. Lett., 31, L06610, doi:10.1029/2003GL019079.

\section{Introduction}

[2] Since 1922 silicic lava flows and exogenous dome growth has occurred at Santiaguito, Guatemala, building a dacitic dome complex $\sim 1200 \mathrm{~m}$ below and $\sim 2500 \mathrm{SW}$ the Santa Maria summit [Rose, 1987]. In the last 80 years, 4 vents with a lateral extent of $\sim 1.5 \mathrm{~km}$ have contributed $\sim 1.1 \mathrm{~km}^{3}$ to the construction of the $\sim 500 \mathrm{~m}$ tall edifice [Rose, 1987; Harris et al., 2003]. Since 1986 activity has been focused at the easternmost Caliente Vent, which was the original locus of dome growth and is thought to most directly overlie the magma supply conduit [Rose, 1972; Rose, 1987].

[3] Explosive activity is a feature of nearly every observation period since the 1970s [Stoiber et al., 1983; Rose, 1987; BVGN, Santiaguito, Global Volcanism Network, 1990-2003]. These events, occurring at intervals ranging from 5 to 100 minutes, vary from short bursts producing $1-$ $3 \mathrm{~km}$ high, white, buoyant clouds to ash-rich emissions lasting up to 20 minutes that occasionally feed small density currents. Vertically-directed pyroclastic eruptions appear to emanate from ring fractures located within and around a dacitic plug of radius $\sim 150 \mathrm{~m}$ [Bluth et al., 2002]. Frequent,

\footnotetext{
${ }^{1}$ HIGP/SOEST, University of Hawaii, Honolulu, Hawaii, USA.

${ }^{2}$ Now at CCRC, University of New Hampshire, Durham, New Hampshire, USA.

${ }^{3}$ CONRED, Guatemala City, Guatemala.

${ }^{4}$ Department of Geological Engineering, Geology and Geophysics Michigan Technological University, Houghton, Michigan, USA.

Copyright 2004 by the American Geophysical Union. 0094-8276/04/2003GL019079\$05.00
}

but usually small, ash-generating events are also caused by the collapse of levees and flow fronts of blocky lava flows on the steep dome [Rose et al., 1976; Harris et al., 2002]. These flows are testament to the continued eruption of juvenile lava, which was estimated at $<0.5 \mathrm{~m}^{3} / \mathrm{s}$ in 2000 [Harris et al., 2002].

[4] Explosive activity observed in Jan. 2003 exhibited repose intervals of 15 to $>60$ minutes. Although Rose [1987] suggested a phreatic origin, new work highlighting unsteady flow in the conduit of volcanic domes [Barmin et al., 2000] indicates that the activity may be related to unsteady extrusion, which can vary on a time scale of hours [Voight et al., 1998]. Here, in an attempt to understand Santiaguito eruption dynamics, we present data that enables us to track changes in plume rise speeds and eruption energies. Such data may assist with mass flux estimates that can be input into models to estimate potential plume height [Sparks et al., 1997]. These results can then be used to model, predict and understand plume dispersion, fallout and aviation hazard, as well as to constrain conduit conditions such as flow dynamics in the ascending, vesiculating magma [e.g., Glaze and Self, 1991; Jaupart, 2000]. In this regard, increased rise velocities imply that a more energetic plume will rise to greater altitudes [e.g., Woods, 1997].

\section{Experiment Overview}

[5] Following the design of Ripepe et al. [2003], we installed an 8-channel thermal-seismo-acoustic array $\sim 1600 \mathrm{~m}$ from the active vent (Figure 1) and started monitoring at 19:30 (local time) on Jan. 8, 2003. Except for three $\sim 10$-minute gaps, acquisition was continuous for $84 \mathrm{~h}$ until Jan. 12 at 08:00. All instruments were deployed on the summit of the Brujo Dome $1600 \mathrm{~m} \pm 100 \mathrm{~m}$ from the active vent. Data from 3 thermal infrared sensors, 1 shortperiod seismometer, and 4 infrasonic microphones were recorded at $122 \mathrm{~Hz}$ with a DataQ DI-700 digitizer connected to a laptop PC.

\subsection{Thermal}

[6] Three thermal infrared $(8-14 \mu \mathrm{m})$ thermometers were aimed at the vent to provide continuous brightness temperature data. Inclination was $29 \pm 3$ and $12 \pm 3^{\circ}$ for two $1^{\circ}$ field-of-view (FOV) instruments (Omega ${ }^{\mathrm{TM}}$ OS554) and $12 \pm 3^{\circ}$ for a single $15^{\circ} \mathrm{FOV}$ thermometer $\left(\mathrm{Omega}^{\mathrm{TM}}\right.$ OS43). For a sensor-to-plume distance of $\sim 1600 \mathrm{~m}$, the two $1^{\circ}$ FOV instruments each viewed areas of $\sim 600 \mathrm{~m}^{2}$ separated by $\sim 420 \mathrm{~m}$, with the lower FOV instrument aimed $\sim 100 \mathrm{~m}$ above the vent. The $15^{\circ} \mathrm{FOV}$ sensor integrated radiance over $\sim 136,000 \mathrm{~m}^{2}$, incorporating the lower $1^{\circ} \mathrm{FOV}$ target area (Figure 1). It should be noted that recorded brightness temperature (as shown in Figure 2a) does not reflect actual plume temperature, but instead corresponds to a thermal radiance averaged over the FOV, which may 


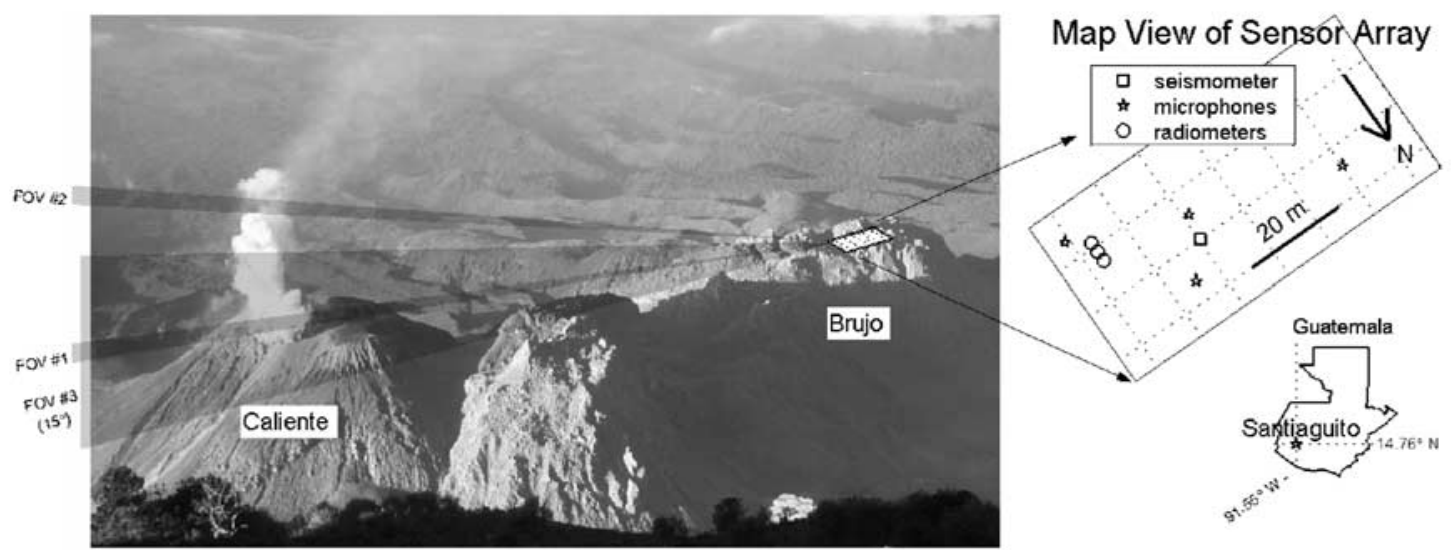

Figure 1. Santiaguito dome viewed from Santa Maria. Active Caliente vent is at left (east) $\sim 1600 \mathrm{~m}$ from the inactive Brujo Dome, where sensors (inset map) were installed. Thermometer FOVs are shown as transparent cones.

including targets of variable temperature and emissivity. Thermal data were contingent upon cloud-free conditions, generally possible only at night.

\subsection{Infrasound}

[7] Four microphones using Panasonic WM-034BY electret condenser elements were deployed as a small-aperture $(\sim 60 \mathrm{~m})$ antenna. These instruments incorporated a band pass filter $(0.1$ to $10 \mathrm{~Hz})$ and a high-pass filter associated with the sensors' FET, inducing a low-frequency corner at $\sim 0.5 \mathrm{~Hz}$. Nevertheless, most of the Santiaguito infrasound appeared to lie in the flat portion of the microphones' response. The multi-element array was used to discriminate volcanic degassing signal from non-volcanic noise through back-azimuth source determination. Wind noise was problematic in $\sim 33 \%$ of our data.

\subsection{Seismic}

[8] A $1 \mathrm{~Hz}$ vertical-component Mark Products L4 seismometer was installed at the acquisition hub. The site response is likely significant because the sensor was buried in ash above porous talus.

\section{Plume Rise Speed}

[9] We utilized delay times between correlated thermal pulses from the $1^{\circ}$ FOV sensors to estimate rise speeds $(V)$ for vertically-directed plumes. The onsets of the thermal transients were characterized by rapid brightness temperature gains of 10 to $30^{\circ} \mathrm{C}$, associated with the leading edge of the hot plume ascending through the FOV. Time delays between thermal onsets $\left(\Delta t_{T_{F O V \# 2}-T_{F O V \# 1}}=\right.$ $\sim 20$ to $80 \mathrm{~s}$ ), divided by the separation distance of the sensors $(\sim 420 \mathrm{~m})$, provided $V$ of 5 to $20 \mathrm{~m} / \mathrm{s}$. These are consistent with the 9 to $24 \mathrm{~m} / \mathrm{s}$ rise speed estimates obtained for 8 explosions recorded with digital video on Jan. 9, 2003.

[10] It is also possible to estimate $V$ using a brightness temperature waveform $T_{b}(t)$ recorded by a single sensor.
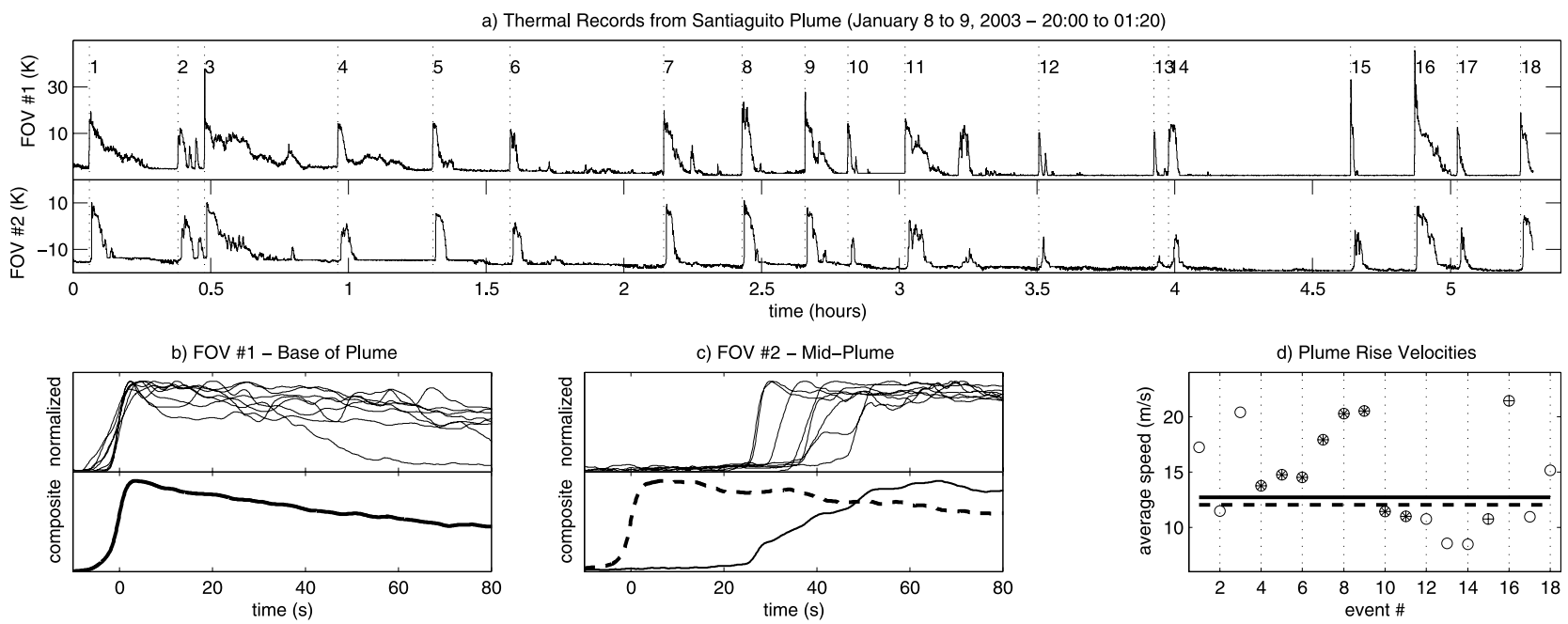

Figure 2. (a) Five-hour thermal time series showing 18 distinct thermal events. (b-c) Thermal waveform stack and composite waveform from 8 consecutive explosions (events \#4-11) recorded with the lower (b) and upper sensors (c). Dotted line is a composite averaged signal (FOV \#2) after time-migration of waveforms. (d) Plume rise velocities are calculated using both delay time between thermal transients (circular symbols) and equation (1) applied to the composite thermal waveforms. 

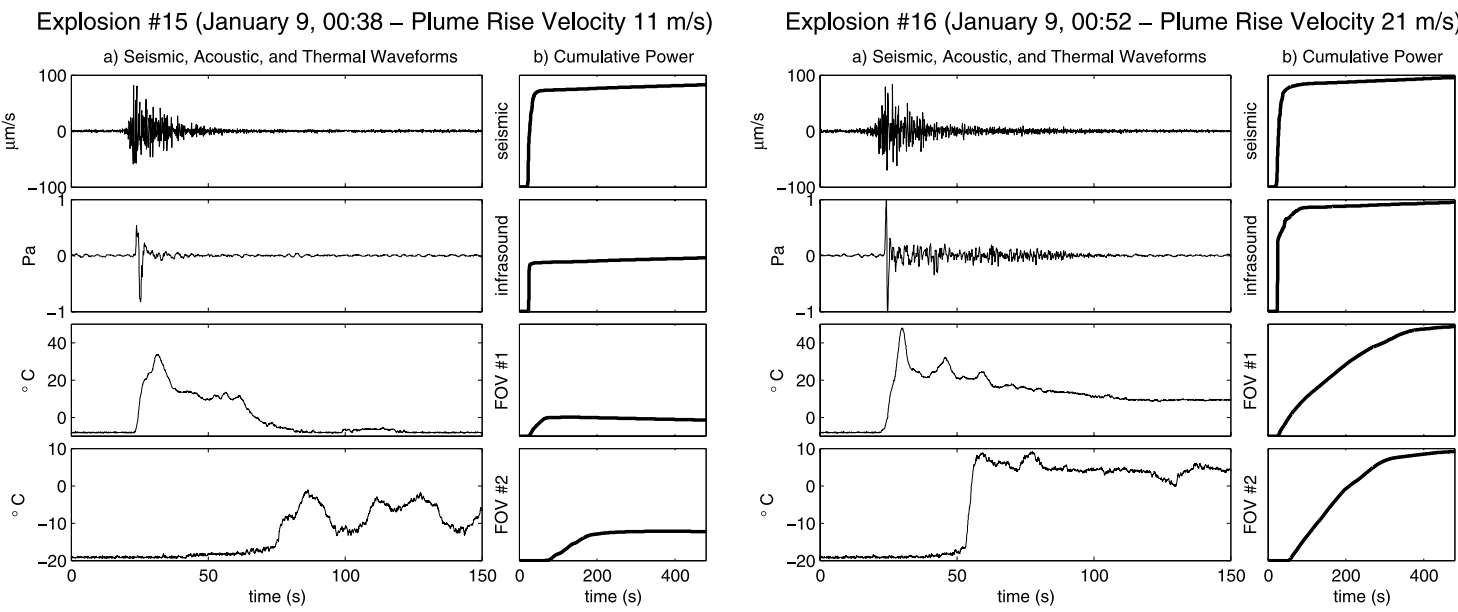

Figure 3. (a) Calibrated seismic, calibrated stacked infrasound, and $1^{\circ} \mathrm{FOV}$ thermal brightness temperature traces for explosion \#15 (left) and \#16 (right). (b) Cumulative power is calculated from equations (2)-(4) and normalized to the larger explosion.

This method (see appendix) uses brightness thermal rate of change $\left(d T_{b} / d t\right)$ during the onset of an explosion as a proxy for $V$ :

$$
V \approx \frac{2 \pi R}{T_{h}^{4}-T_{c}^{4}}\left(\frac{d T_{b}}{d t} T_{b}^{3}\right)_{\max }
$$

$R$ is the FOV radius and $T_{h}$ and $T_{c}$ are the maximum plume and background temperatures, respectively. Average velocities from equation (1) compare favorably with rise speeds determined from delay times (Figure 2d). This method further indicates that average velocity between FOV \#1 $(12 \mathrm{~m} / \mathrm{s})$ and FOV \#2 $(11 \mathrm{~m} / \mathrm{s})$ demonstrates insignificant deceleration. Because we would expect the plume to decelerate within a near-vent gas thrust zone and the plume to stagnate at an altitude of horizontal dispersion [Cioni et al., 2000; Carey and Bursik, 2000], we conclude that the plume is buoyantly driven 100 to $500 \mathrm{~m}$ above the dome.

\section{Thermal-Seismo-Acoustic Energy Partitioning}

[11] A comparison of $V$ with thermal flux and radiated elastic wave field provides additional constraints on eruption dynamics. We estimate the relative energy contributions for a suite of explosions occurring during periods of negligible cloud cover (high quality thermal records) and relatively windless conditions (good infrasonic records).

[12] We assess the relative acoustic energy $\left(E_{A}\right)$ and seismic energy $\left(E_{S}\right)$ contributions because absolute estimates are beyond the capabilities of our data. Potential seismic source anisotropy, complex propagation filters, and uncertain site response preclude absolute estimates of seismic moment for explosion events. Similarly the timeintegrated acoustic power may be precisely estimated only for an isotropic source that radiates into a homogeneous atmosphere. Because of these uncertainties we opt to compare normalized energy contributions, which enable inter-comparison of relative energy partitioning within a suite of explosions. Normalizing the elastic energy relationships presented in J. B. Johnson and R. C. Aster (Volcanic acoustic efficiency of Strombolian eruptions, submitted to Journal of Volcanology and Geothermal Research, 2004), we simplify the cumulative acoustic energy to be proportional to the time-integrated, squared pressure trace [Pierce, 1981].

$$
E_{A} \approx \int \Delta P(t)^{2} d t
$$

$\Delta P(t)$ is the excess pressure time history. Similarly, by assuming a predominance of body waves, we make simplifications to Boatwright [1980], so that cumulative seismic energy is proportional to the squared velocity trace $U(t)^{2}$, or time-integrated kinetic energy.

$$
E_{S} \approx \int U(t)^{2} d t
$$

To obtain a comparative measure of thermal energy, we use the time-integrated thermal intensity, taken from the brightness temperature waveforms, as a proxy for relative heat flux. We are interested in comparing relative thermal contributions and thus use the Stefan Boltzmann Equation to recover thermal radiance. The cumulative thermal energy $\left(E_{T}\right)$ is calculated for unity emissivity after removing thermal contributions associated with the background temperature:

$$
E_{T} \approx \int T_{b}^{4}-T_{c}^{4} d t
$$

To facilitate comparison of events, the relative energy estimates are calculated from equations (2)-(4) for a 6-minute window and then scaled to the largest explosion within the comparison group (Figures 3 and 4).

[13] Two individual events, medium explosion \#15 and larger explosion \#16 (Figure 3), illustrate the variability in energy partitioning. Despite possessing seismic traces with similar envelope and cumulative energy, \#16 radiates nearly twice the acoustic energy and appears to output significantly more heat than $\# 15$. Sustained infrasound provides the primary contribution to the relatively high cumulative acoustic energy, whereas both increased thermal amplitude 

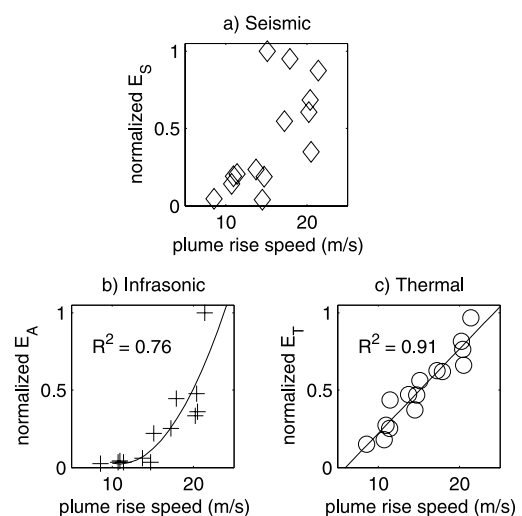

Figure 4. Comparison of rise speed with normalized (a) seismic, (b) stacked acoustic (4 sensors), and (c) thermal energy $\left(15^{\circ} \mathrm{FOV}\right)$ for 15 consecutive explosions on Jan. 8 to 9 (20:00 to $01: 00)$.

and signal duration lead to the elevated cumulative thermal flux. The extended duration of the infrasound produced by \#16 ( 70 s) compared to \#15 ( 15 s), reflects continued perturbation of the atmosphere, that can be attributed to an extended-duration vigorous degassing source [Johnson et al., 2003]. Presumably the longer-duration source is also able to vent larger quantities of hot gas into the atmosphere. Because a voluminous hot plume is more efficient at retaining its heat than a small hot plume - less surface area per unit volume - it follows that \#16 should exhibit elevated brightness temperatures. This hotter plume will maintain a lower average density and thus rise with a greater buoyant rise speed [Turner, 1973]. Indeed, inferred rise speeds prove to be nearly twice as fast for \#16.

[14] A clear relationship exists $\left(\mathrm{R}^{2}=0.91\right)$ between $V$ and $E_{T}$ (Figure 4), suggesting that the quantity $E_{T}$ may be used as a proxy for relative thermal flux and/or explosion magnitude. There also appears to be reasonable correlation $\left(\mathrm{R}^{2}=0.76\right)$ between $V$ and $E_{A}$ using a quadratic fit, where the larger events are also effective at radiating louder, longer-duration infrasound.

[15] The link between $V$ and $E_{S}$ is less clear and we do not feel confident to fit a curve to these data. We propose that seismic energy is not always an effective measure of eruption magnitude because much of the seismicity may be generated by internal brittle rock fracture, intermittent fluid flow, as suggested by Bluth et al. [2002], or rock falls on the dome. These sources may be completely independent from the net explosive gas output. We suggest that seismicity can also be underrepresented during low impulsivity explosions. Passive degassing would induce lower source stresses and hence be less efficient for producing high amplitude seismic waves.

\section{Conclusion}

[16] We demonstrate that plume rise speeds at volcanoes can be reliably calculated using two infrared thermometers. At Santiaguito, constant rise speeds ranging from 8 to $20 \mathrm{~m} / \mathrm{s}$ are inferred to be buoyantly driven $\sim 100$ to $500 \mathrm{~m}$ above the dome. Because rise speeds are correlated with the cumulative thermal flux, hotter, faster rising plumes likely indicate a more voluminous eruptive flux. Though larger magnitude eruptions tend to be associated with greater acoustic energy, they are not well correlated with seismic energy release.

\section{Appendix}

[17] We assume a FOV composed of a vertically rising isothermal plume $\left(T_{h}\right)$ with fractional coverage $f_{\text {plume }}$, superimposed upon a cold background $\left(T_{c}\right)$. Effective radiation brightness temperature $\left(T_{b}\right)$ is then $\left(T_{c}^{4}+f(t)_{\text {plume }}\left(T_{h}^{4}-\right.\right.$ $\left.\left.T_{c}^{4}\right)\right)^{1 / 4}$ [Crisp and Baloga, 1990] and the rate of change $\left(d T_{b} / d t\right)$ is $\frac{1}{4} \frac{d f_{\text {plume }}}{d t}\left(\frac{T_{h}^{4}-T_{c}^{4}}{T_{b}^{3}}\right)$. Thus the change in fractional coverage $\left(d f_{\text {plume }} / d t\right)$ is $\frac{4}{T_{h}^{4}-T_{c}^{4}}\left(\frac{d T_{b}}{d t}\right) T_{b}^{3}$.

[18] We next assume that a plume with planar upper edge ascends at constant velocity $(V)$ across a circular FOV of radius $(R)$. The maximum fractional change occurs when $f_{\text {plume }}=50 \%$ and $\left(\frac{d f_{\text {plume }}}{d t}\right)_{\max } \approx \frac{2 V}{\pi R}$. It follows that

$$
V \approx \frac{\pi R}{2}\left(\frac{d f_{\text {plume }}}{d t}\right)_{\max }=\frac{2 \pi R}{T_{h}^{4}-T_{c}^{4}}\left(\frac{d T_{b}}{d t} T_{b}^{3}\right)_{\max }
$$

[19] Acknowledgments. We thank CONRED, INSIVUMEH, S. Bonis, R. Wright, L. Flynn, M. Davies and L. Clabaugh for support in Guatemala. Funding was through NSF EAR-0106349.

\section{References}

Barmin, A., O. Melnik, and R. S. J. Sparks (2000), Periodic behavior in lava dome eruptions, Earth Planet. Sci. Lett., 199(1-2), 173-184.

Bluth, G. J., Y. K. Branan, W. I. Rose, I. M. Watson, and O. Matias (2002), Observations of Santiaguito's eruptive and passive emissions, Eos Trans. $A G U, 83(47)$, Fall Meet Suppl., Abstract V72C-03.

Boatwright, J. A. (1980), Spectral theory for circular seismic sources: Simple estimates of source dimension, dynamic stress drop, and radiated seismic energy, Bull. Seismol. Soc. Am., 70(1), 1-27.

Carey, S., and M. Bursik (2000), Volcanic plumes, in Encyclopedia of Volcanoes, edited by H. Sigurdson et al., pp. 527-554, Academic, San Diego, Calif.

Cioni, R., P. Marianelli, R. Santacroce, and A. Sbrana (2000), Plinian and subplinian eruptions, in Encyclopedia of Volcanoes, edited by H. Sigurdson et al., pp. 477-494, Academic, San Diego, Calif.

Crisp, J., and S. Baloga (1990), A model for lava flows with two thermal components, J. Geophys. Res., 95, 1255-1270.

Glaze, L. S., and S. Self (1991), Ashfall dispersal for the 16 September 1986, eruption of Lascar, Chile, calculated by a turbulent diffusion model, Geophys. Res. Lett., 18(7), 1237-1240.

Harris, A. J. L., L. P. Flynn, O. Matías, and W. I. Rose (2002), The thermal stealth flows of Santiaguito: Implications for the cooling and emplacement of dacitic block lava flows, Geol. Soc. Am. Bull., 114(5), 533-546.

Harris, A. J. L., W. I. Rose, and L. P. Flynn (2003), Temporal trends in lava dome extrusion at Santiaguito 1922-2000, Bull. Volcanol., 65(2-3), $77-89$.

Jaupart, C. (2000), Magma ascent at shallow levels, in Encyclopedia of Volcanoes, edited by H. Sigurdson et al., pp. 237-245, Academic, San Diego, Calif.

Johnson, J. B., R. C. Aster, M. C. Ruiz, S. D. Malone, P. J. McChesney, J. M. Lees, and P. R. Kyle (2003), Interpretation and utility of infrasonic records from erupting volcanoes, J. Volcanol. Geotherm. Res., 121, 1563.

Pierce, A. D. (1981), Acoustics: An Introduction to Its Physical Principles and Applications, 642 pp., McGraw-Hill, New York.

Ripepe, M., A. J. L. Harris, and R. Carniel (2003), Thermal, seismic and infrasonic insights into conduit process at Stromboli volcano, J. Volcanol. Geotherm. Res., 118, 207-285.

Rose, W. I. (1972), Santiaguito volcanic dome, Guatemala, Geol. Soc. Am. Bull., 83, 1413-1434.

Rose, W. I. (1987), Volcanic activity at Santiaguito volcano, 1976-1984, Spec. Pap. Geol. Soc. Am., 212, 17-27. 
Rose, W. I., T. Pearson, and S. Bonis (1976), Nuée Ardente eruption from the foot of a dacite lava flow, Santiaguito Volcano, Guatemala, Bull. Volcanol., 40, 23-38.

Sparks, R. S. J., M. I. Bursik, S. Carey, J. S. Gilbert, L. S. Glaze, H. Sigurdsson, and A. W. Woods (1997), Volcanic Plumes, John Wiley, Hoboken, N. J.

Stoiber, R. E., L. L. Malinconico, and S. N. Williams (1983), Use of the correlation spectrometer at volcanoes, in Forecasting Volcanic Events, pp. 425-444, Elsevier Sci., Norwell, Mass.

Turner, J. S. (1973), Buoyancy Effects in Fluids, 367 pp., Cambridge Univ. Press, New York.

Voight, B., R. P. Hoblitt, A. B. Clarke, A. B. Lockhart, A. D. Miller, L. Lynch, and J. McMahon (1998), Remarkable cyclic ground deformation monitored in real time on Montserrat and its use in eruption forecasting, Geophys. Res. Lett., 25(18), 3405-3408.
Woods, A. W. (1997), Observations and models of eruption columns, Geol. Soc. Spec. Publ., 145, 91-114.

A. J. L. Harris and S. T. M. Sahetapy-Engel, HIGP/SOEST, University of Hawaii, 1680 East-West Road, Honolulu, HI 96822, USA.

J. B. Johnson, CCRC, University of New Hampshire, Durham, NH 03824, USA. (jeff.johnson@unh.edu)

W. I. Rose, Department of Geological Engineering, Geology and Geophysics, Michigan Technological University, 1400 Townsend Drive, Houghton, MI 49931, USA.

R. Wolf, CONRED, Avenida Hincapie 21-72, Zone 13, Guatemala City, Guatemala. 